\title{
Risk factors and predictors associated with the severity of COVID-19 in China: a systematic review, meta-analysis, and meta- regression
}

\author{
Tao Zhang', Wei-Sen Huang ${ }^{2}$, Weijie Guan ${ }^{3}$, Ziying Hong ${ }^{3}$, Jiabo Gao ${ }^{3}$, Guoying Gao ${ }^{3}$, Guofeng Wu ${ }^{4}$, \\ Yin-Yin Qin ${ }^{3,5}$
}

${ }^{1}$ Nanshan School, Guangzhou Medical University, Guangzhou, China; ${ }^{2}$ School of Pharmaceutical Sciences, Guangzhou Medical University, Guangzhou, China; ${ }^{3}$ State Key Laboratory of Respiratory Disease, National Clinical Research Center for Respiratory Disease, Guangzhou Institute of Respiratory Health, the First Affiliated Hospital of Guangzhou Medical University, Guangzhou, China; ${ }^{4}$ Department of Medicine, Liwan Central Hospital of Guangzhou, Guangzhou, China; ${ }^{5}$ Pulmonary and Critical Care Medicine, Shunde Affiliated Hospital of Guangzhou Medical University (Lecong Hospital of Shunde District), Foshan, China

Contributions: (I) Conception and design: T Zhang, WS Huang, G Wu, YY Qin; (II) Administrative support: YY Qin, G Wu; (III) Provision of study materials or patients: T Zhang, WS Huang, YY Qin, W Guan, G Gao; (IV) Collection and assembly of data: WS Huang, W Guan, Z Hong, J Gao; (V) Data analysis and interpretation: WS Huang, W Guan, Z Hong, J Gao, G Gao; (VI) Manuscript writing: All authors; (VII) Final approval of manuscript: All authors.

Correspondence to: Yin-Yin Qin, PhD. State Key Laboratory of Respiratory Disease, National Clinical Research Center for Respiratory Disease, Guangzhou Institute of Respiratory Health, the First Affiliated Hospital of Guangzhou Medical University, Guangzhou 510120, China; Pulmonary and Critical Care Medicine, Shunde Affiliated Hospital of Guangzhou Medical University (Lecong Hospital of Shunde District), Foshan, China. Email: 13610047638@163.com; Guofeng Wu. Department of Medicine, Liwan Central Hospital of Guangzhou, Guangzhou 510170, China. Email: wgf13650836993@163.com.

\begin{abstract}
Since December 2019, the pneumonia cases infected with 2019 novel coronavirus have appeared, posing a critical threat to global health. In this study, we performed a meta-analysis to discover the different clinical characteristics between severe and non-severe patients with COVID-19 to find the potential risk factors and predictors of this disease's severity, as well as to serve as a guidance for subsequent epidemic prevention and control work. PubMed, Cochrane Library, Medline, Embase and other databases were searched to collect studies on the difference of clinical characteristics of severe and non-severe patients. Meta-analysis was performed using RevMan 5.3 software, and the funnel plots could be made to evaluate the publication bias. $\mathrm{P}>0.05$ means no statistical significance. Furthermore, a meta-regression analysis was performed by using Stata 15.0 to find the potential factors of the high degree of heterogeneity $\left(\mathrm{I}^{2}>50 \%\right)$. Sixteen studies have been included, with 1,172 severe patients and 2,803 non-severe patients. Compared with non-severe patients, severe patients were more likely to have the symptoms of dyspnea, hemoptysis, and the complications of ARDS, shock, secondary infection, acute kidney injury, and acute cardiac injury. Interestingly, the former smokers were more prevalent in severe cases as compared to non-severe cases, but there was no difference between the two groups of 'current smokers'. Except for chronic liver disease and chronic kidney disease, the underlying comorbidities of hypertension, diabetes, cardiovascular disease, chronic obstructive pulmonary disease (COPD), malignancy, cerebrovascular disease, and HIV can make the disease worse. In terms of laboratory indicators, the decreased lymphocyte and platelet count, and the increased levels of white blood cell (WBC), D-dimer, creatine kinase, lactate dehydrogenase, procalcitonin, alanine aminotransferase, aspartate aminotransferase, and C-reactive protein were more prevalent in severe patients. Meta-regression analysis showed that patient age, gender, and proportion of severe cases did not significantly impact on the outcomes of any clinical indexes that showed high degree of heterogeneity in the meta-analysis. In conclusion, the severity of COVID-19 could be evaluated by, radiologic finding, some symptoms like dyspnea and hemoptysis, some laboratory indicators, and smoking history, especially the exsmokers. Compared with non-severe patients, severe patients were more likely to have complications and
\end{abstract}


comorbidities including hypertension, cardiovascular disease etc., which were the risk factors for the disease to be severer, but the chronic liver disease and chronic kidney disease were not associated the severity of COVID-19 in China.

Keywords: COVID-19; clinical characteristics; clinical features; meta-analysis; meta-regression

Submitted Apr 23, 2020. Accepted for publication Oct 16, 2020.

doi: $10.21037 /$ jtd-20-1743

View this article at: http://dx.doi.org/10.21037/jtd-20-1743

\section{Introduction}

Since December 2019, the pneumonia cases infected with 2019 novel coronavirus have appeared, posing a critical threat to global health. As of April 15, 2020, in China, the cumulative number of laboratory confirmed patients reached 83,745 , including existing confirmed 2,004 cases (1,500 cases from abroad), 78,389 cured cases, and 3,352 deaths, etc. Fortunately, the recent decrease in the number of new cases means that the spread of the epidemic in China has been effectively controlled and the rate of patient treatment has increased significantly.

Recently, the basic, clinical and epidemiological research on 2019 novel coronavirus pneumonia (COVID-19) has been emerging, but there is a lack of a systematic review and meta-analysis to combine them comprehensively. In order to find the potential risk factors, predictors and prognosis of this disease's severity and better distinguish the severe patients from the non-severe patients based on the basic clinical characteristics at early stages so that reduce the mortality, we systematically summarize the existing main research related to discover the different clinical characteristics between severe and non-severe patients in the outbreak of COVID-19, with a view to serve as a guidance for subsequent epidemic prevention and control work.

We present the following article in accordance with the PRISMA reporting checklist (available at http://dx.doi. org/10.21037/jtd-20-1743).

\section{Methods}

\section{Literature search strategy}

The databases of PubMed, Embase and the Cochrane Library were searched to collect relevant studies about discovering the difference of clinical characteristics between severe and non-severe patients in the outbreak of COVID-19 in China. The search period was from January 1,
2020 to April 10, 2020. The search terms "clinical features" or "clinical characteristics" AND "2019 novel coronavirus" or "2019-nCoV" or "novel coronavirus" or "SARS-CoV-2" or "COVID-19" were used. To identify missing studies, we had checked the reference list for each selected paper.

\section{Study selection and data extraction}

The articles involving the comparison of clinical characteristics between severe and non-severe patients (ICU/non-ICU data as the second choice if severe/ non-severe data was not provided) such as etiology, epidemiology, symptoms, imaging characteristics, blood indicators, comorbidities, complications and treatment methods were eligible for the present meta-analysis.

Non-severe patients included: (I) patients with mild to moderate disease; (II) non-ICU patients. Severe patients included: (I) patients with severe to critically severe disease; (II) patients entering ICU for treatment. The severity of disease was classified as follows according to the 5 th edition of the guidelines for the diagnosis and treatment of COVID-19 (1): (I) mild type: patients with mild clinical symptoms and without abnormal CT findings; (II) moderate type: patients with symptoms of fever, cough, etc., and having abnormal changes on CT imagine; (III) severe type: patients presenting with any one of following criteria: (i) respiratory distress, respiratory rate $\geq 30$ per min; (ii) in resting condition, oxygen saturation of finger $\leq 93 \%$; (iii) partial pressure of oxygen in arterial blood/fraction of inspired oxygen $\leq 300 \mathrm{mmHg}$; (IV) critical type: any one of the following conditions has to be met: (i) respiratory failure occurs and mechanical ventilation is required; (ii) shock; (iii) patients with multiple organ failure needing ICU monitoring treatment.

Studies were excluded as follows: (I) duplicate publications; (II) reviews, editorials; case reports, letters, and comments; (III) only on the cases of children, pregnant women, older patients, infants, and some special groups 
with special disease like HIV, etc.; (IV) no full-text; etc.

The clinical characteristics of severe and non-severe patients in this meta-analysis were compared, and the extracted information included: (I) basic information of the research, including the title, first author, the time and the journal of publication; (II) clinical characteristics of patients with COVID-19, including the number of patients in each group, the age, gender, and symptoms, complications, comorbidities etc. of this disease.

\section{Article quality assessment}

All articles were evaluated and compared independently by two evaluators. If there are any inconsistencies, a discussion should be taken or an independent expert was further consulted. The NRCT was scored according to NewcastleOttawa Scale (NOS) quality criteria (2), and the highest quality of the literature was 9 stars and the lowest 0 stars.

\section{Statistical method}

Meta-analysis was performed by using RevMan 5.3 software. The odds ratio [OR, 95\% confidence intervals (CI)] was used to describe the ratio of the probability of the Coronavirus occurring in severe patients versus nonsevere patients. Before the meta-analysis, the heterogeneity test was performed, if $\mathrm{I}^{2}<50 \%, \mathrm{P}>0.1$, suggesting that the degree of heterogeneity was low, and the meta-analysis was performed using the fixed effect model (FE); otherwise, the random effects model (RE) was used. If necessary, we should perform subgroup analysis. The funnel plots could be made to evaluate the publication bias. $\mathrm{P}>0.05$ means no statistical significance.

Furthermore, a meta-regression analysis was performed to assess the potential effect of demographic and clinical variables (patient age, male gender, proportion of severe cases) on the outcomes of some clinical indexes that showed high degree of Heterogeneity $\left(\mathrm{I}^{2}>50 \%\right)$ in the meta-analysis.

\section{Results}

\section{Literature search results and document characteristics}

In order to find the possible risk factors and predictors of the severity in COVID-19 to better distinguish the severe patients from the non-severe patients based on the basic clinical characteristics in the future epidemic prevention and control work, we use meta-analysis to combine some results of demographic and clinical characteristics of each study, including gender, smoking status, symptoms, complications, comorbidities, laboratory indicators, and the prognosis to observe the difference of them between the severe and nonsevere cases.

A total of 1,911 related publications were obtained in the initial examination. After layer-by-layer screening, 16 retrospective studies (3-18) including totally 3,975 patients met the inclusion criteria, of which 1,172 were in the group of severe patients and 2,803 were in the group of nonsevere patients. The literature screening process and results were shown in Figure 1, and the basic characteristics and information of the 16 studies were shown in Table 1.

\section{Demographics and clinical characteristics of patients with COVID-19}

Through subgroup analysis, we found that males were more prevalent in severe group $(\mathrm{OR}=1.34, \mathrm{P}=0.0001)$. Interestingly, the previous smoking history (ex-smoking) in the two groups of patients was statistically different (OR $=3.29, \mathrm{P}=0.003$ ), but the difference in current smoking had no statistical significance $(\mathrm{P}=0.17)$. The most common symptoms at onset of illness in many studies (3-18) were fever, cough, myalgia, dyspnea and fatigue; less common symptoms were nausea, vomiting, headache, diarrhea, sputum production, hemoptysis and abdominal pain etc. Compared with non-severe patients, severe patients were more likely to have the symptoms of dyspnea $(\mathrm{OR}=5.52$, $\mathrm{P}<0.00001)$, hemoptysis $(\mathrm{OR}=3.76, \mathrm{P}=0.0003)$, nausea and vomiting $(\mathrm{OR}=1.73, \mathrm{P}=0.02)$, muscle ache $(\mathrm{OR}=1.67$, $\mathrm{P}=0.04)$, and dizziness $(\mathrm{OR}=1.91, \mathrm{P}=0.008)$ (especially dyspnea and hemoptysis), but the difference of symptoms such as cough $(\mathrm{P}=0.42)$, fever $(\mathrm{P}=0.06)$, highest temperature $(\mathrm{P}=0.88)$, diarrhea $(\mathrm{P}=0.07)$, anorexia $(\mathrm{P}=0.18)$, fatigue $(\mathrm{P}=0.27)$, headache $(\mathrm{P}=0.05)$, sputum production $(\mathrm{P}=0.13)$, pharyngalgia $(\mathrm{P}=0.58)$, rhinorrhea $(\mathrm{P}=0.16)$, chest pain $(\mathrm{P}=0.09)$, and abdominal pain $(\mathrm{P}=0.11)$ between the two groups had no statistical significance.

Compared with non-severe patients, severe patients had significantly higher risk to have the complications of ARDS $(\mathrm{OR}=34.45, \mathrm{P}<0.00001)$, AKI $(\mathrm{OR}=7.70, \mathrm{P}=0.002)$, acute cardiac injury $(\mathrm{OR}=6.35, \mathrm{P}=0.03)$, secondary infection $(\mathrm{OR}=9.21, \mathrm{P}=0.04)$, and shock $(\mathrm{OR}=33.18, \mathrm{P}<0.00001)$, and more likely to have the underlying comorbidities $(\mathrm{OR}=2.77, \mathrm{P}<0.00001)$, like hypertension $(\mathrm{OR}=2.50$, $\mathrm{P}<0.00001)$, diabetes $(\mathrm{OR}=2.06, \mathrm{P}<0.0001)$, cardiovascular 


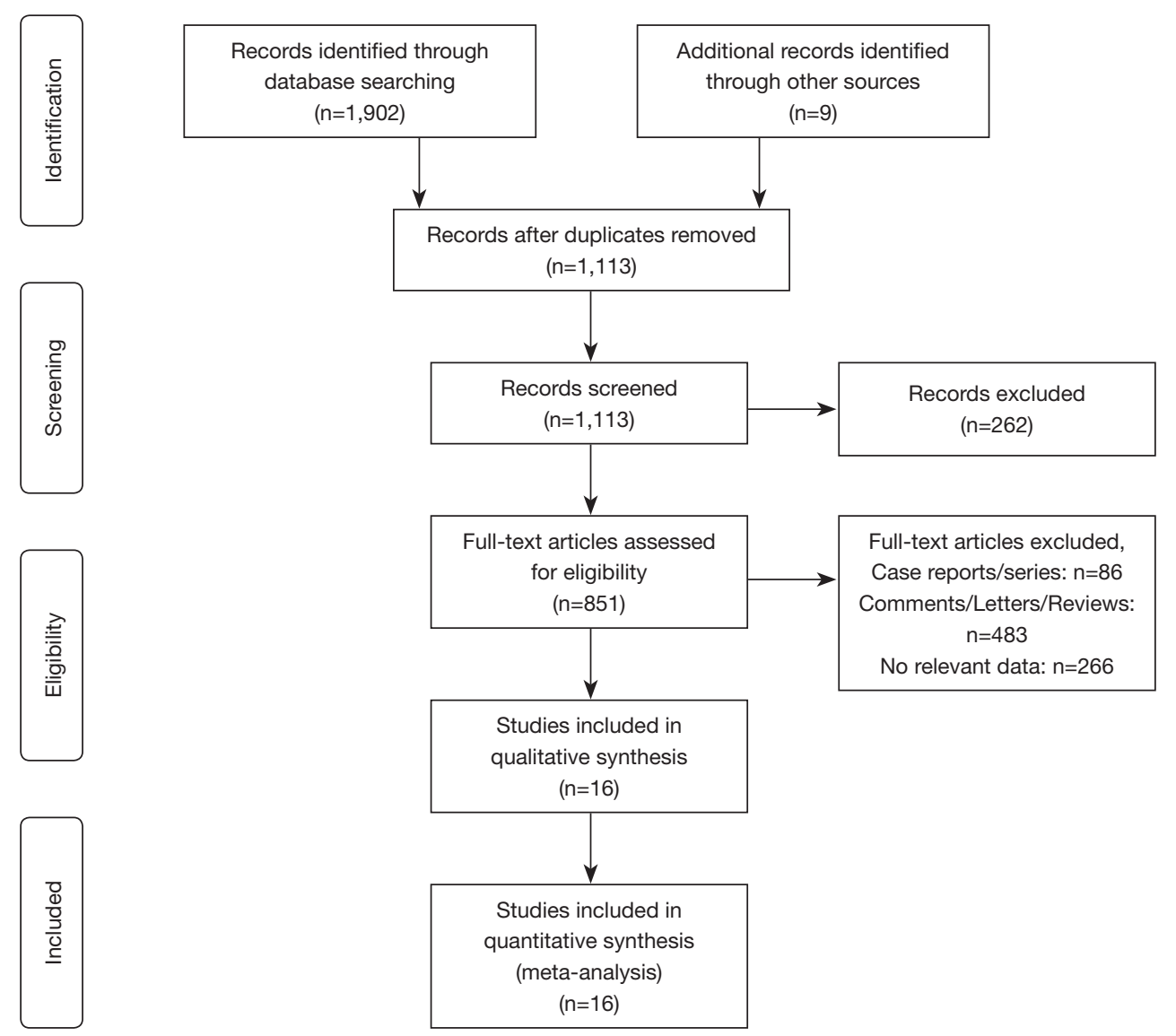

Figure 1 Literature screening flow diagram.

disease $(\mathrm{OR}=3.53, \mathrm{P}<0.00001)$, cerebrovascular disease $(\mathrm{OR}=2.88, \mathrm{P}=0.0003)$, malignancy $(\mathrm{OR}=1.66, \mathrm{P}=0.03)$, chronic obstructive pulmonary disease $(\mathrm{COPD})(\mathrm{OR}=4.67$, $\mathrm{P}<0.00001)$, and HIV or other immunodeficiency disease $(\mathrm{OR}=3.28, \mathrm{P}=0.02)$ (Table 2).

In Figure 2, the funnel plots demonstrated symmetrical distributions of the effect size of cardiovascular disease, malignancy, chronic liver disease, and chronic kidney disease on either side of the pooled estimate, which indicated that the publication bias was not significant.

\section{Radiologic and laboratory findings}

In Table 2, we could find that severe patients have lower Lymphocyte count $(\mathrm{OR}=3.65, \mathrm{P}<0.00001)$ and platelet count $(\mathrm{OR}=2.48, \mathrm{P}<0.00001)$, as well as higher levels of $\mathrm{D}$-dimer $(\mathrm{OR}=4.90, \mathrm{P}=0.006)$, Lactate dehydrogenase $(\mathrm{LDH})(\mathrm{OR}=5.57, \mathrm{P}<0.00001)$, C-reactive protein (CRP) $(\mathrm{OR}=4.33, \mathrm{P}=0.0001)$, creatine kinase $(\mathrm{OR}=2.50$,
$\mathrm{P}<0.00001)$, white blood cell (WBC) count $(\mathrm{OR}=3.57$, $\mathrm{P}=0.0004)$, procalcitonin ( $\mathrm{PCT})(\mathrm{OR}=3.09, \mathrm{P}<0.00001)$, alanine aminotransferase (ALT) $(\mathrm{OR}=1.89, \mathrm{P}=0.0003)$, and aspartate aminotransferase (AST) $(\mathrm{OR}=3.09, \mathrm{P}<0.00001)$ as compared to non-severe patients. In terms of chest CT, we found that severe patients were more likely to yield more prominent radiologic abnormalities like bilateral lung involvement $(\mathrm{OR}=4.84, \mathrm{P}<0.00001)$.

\section{The treatments and prognosis between severe patients and non-severe patients}

The most commonly used treatments in these studies included antiviral therapy, corticosteroid, invasive mechanical ventilation (IMV), noninvasive ventilation (NIV), and continuous kidney replacement therapy (CKRT), etc., in which we found that except for use of traditional Chinese medicine $(\mathrm{P}=0.68)$ and antiviral therapy $(\mathrm{P}<0.0001)$, these therapies showed above were used much more 


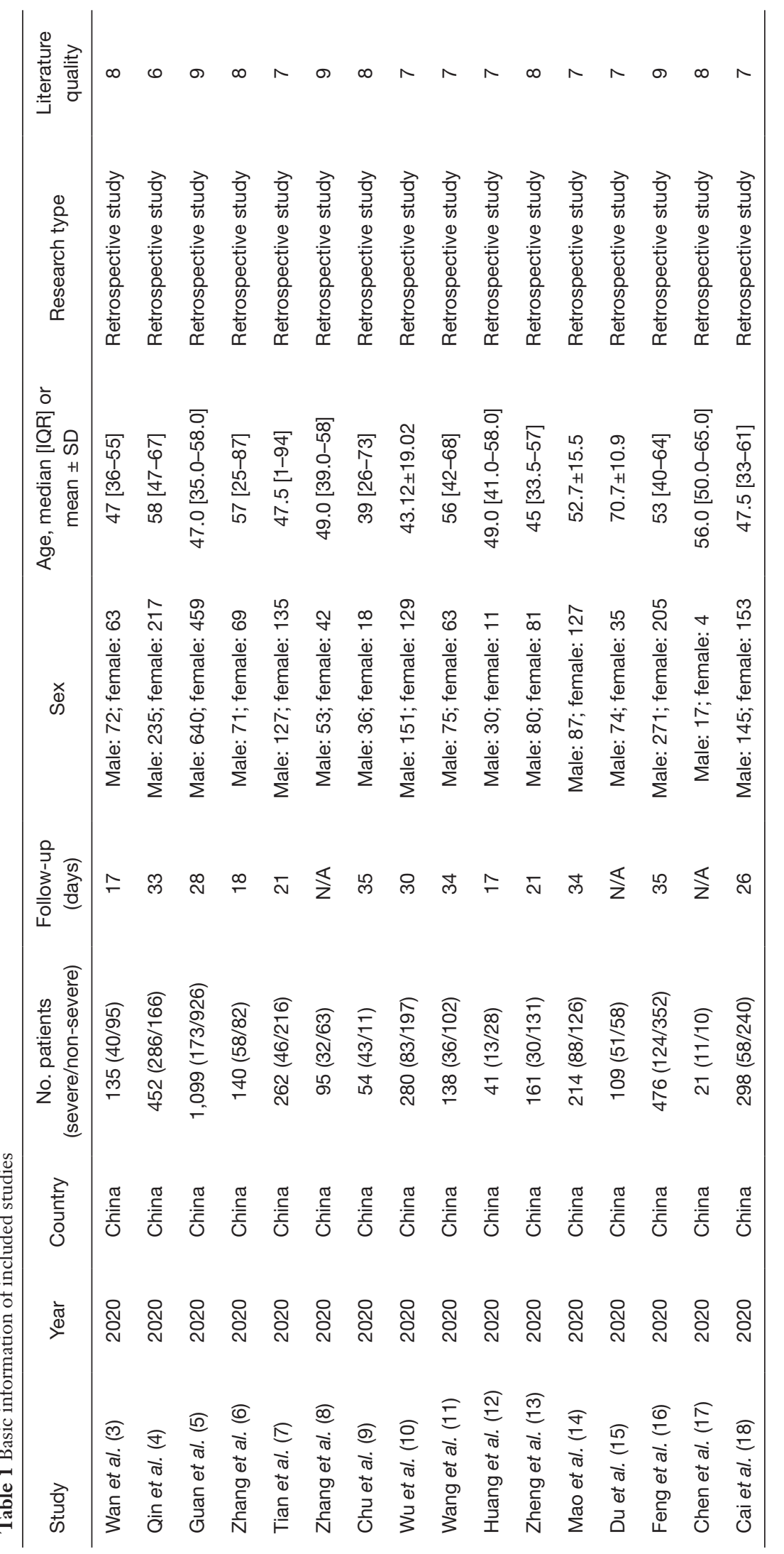


Table 2 The difference between severe and non-severe patients in demographics and clinical characteristics

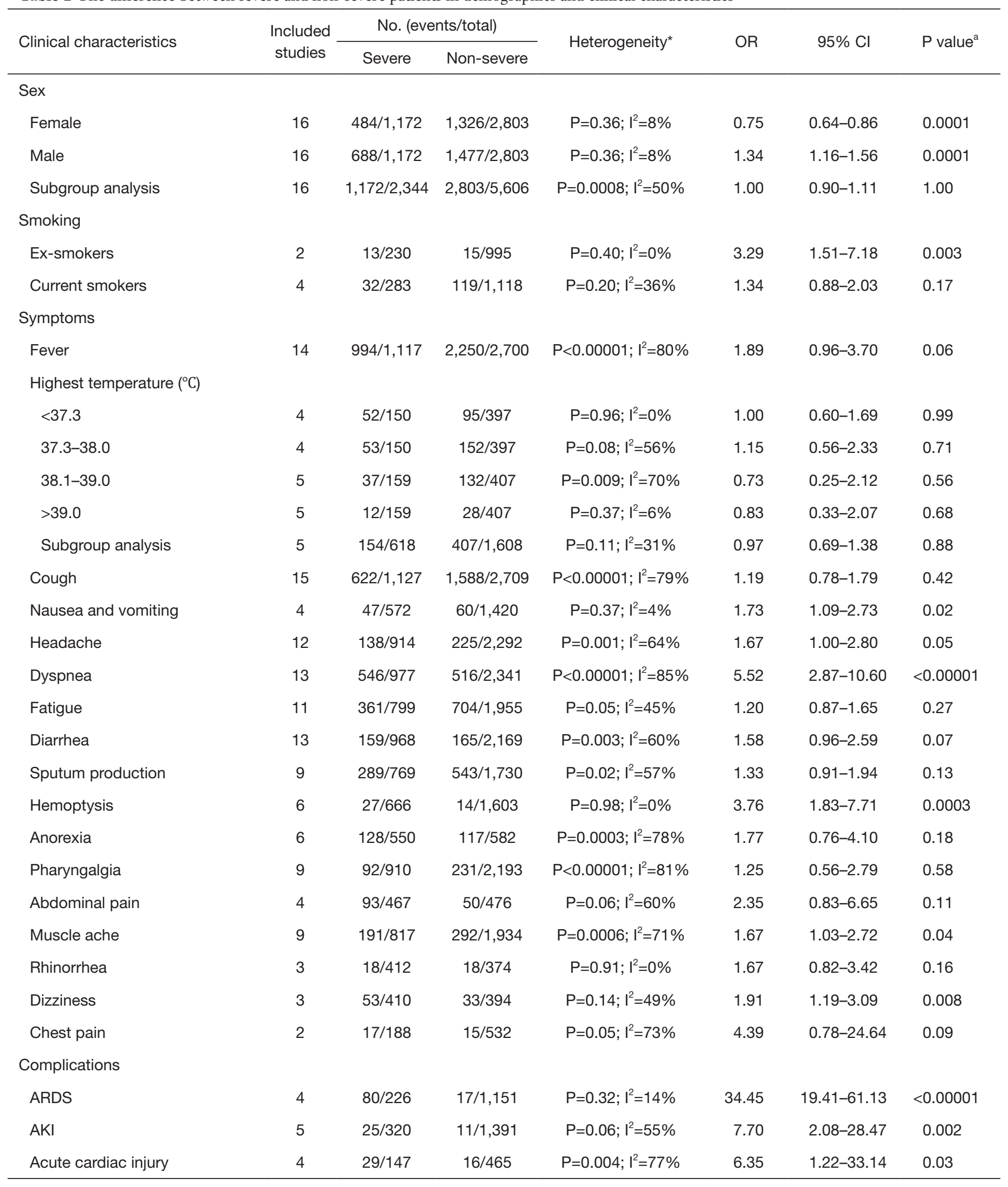

Table 2 (continued) 
Table 2 (continued)

\begin{tabular}{|c|c|c|c|c|c|c|c|}
\hline Clinical characteristics & $\begin{array}{l}\text { Included } \\
\text { studies }\end{array}$ & \multicolumn{2}{|c|}{ No. (events/total) } & Heterogeneity* & OR & $95 \% \mathrm{Cl}$ & $P$ value ${ }^{a}$ \\
\hline Shock & 5 & $27 / 345$ & $1 / 1,348$ & $P=0.59 ; I^{2}=0 \%$ & 33.18 & $10.28-107.05$ & $<0.00001$ \\
\hline Secondary infection & 4 & $52 / 214$ & $24 / 670$ & $P=0.55 ; I^{2}=0 \%$ & 9.21 & $5.48-15.48$ & $<0.00001$ \\
\hline \multicolumn{8}{|l|}{ Comorbidities } \\
\hline Hypertension & 12 & $334 / 968$ & $372 / 2,316$ & $P=0.003 ; I^{2}=61 \%$ & 2.50 & $1.78-3.51$ & $<0.00001$ \\
\hline Diabetes & 12 & $169 / 968$ & $179 / 2,316$ & $P=0.07 ; I^{2}=40 \%$ & 2.06 & $1.46-2.91$ & $<0.0001$ \\
\hline Cardiovascular disease & 9 & $88 / 818$ & $73 / 2,122$ & $P=0.72 ; I^{2}=0 \%$ & 3.53 & $2.49-5.01$ & $<0.00001$ \\
\hline COPD & 9 & $42 / 843$ & $22 / 2,077$ & $P=0.80 ; I^{2}=0 \%$ & 4.67 & $2.73-7.99$ & $<0.00001$ \\
\hline Chronic kidney disease & 8 & 20/899 & $25 / 2,009$ & $P=0.18 ; I^{2}=31 \%$ & 1.26 & $0.70-2.28$ & 0.45 \\
\hline Cerebrovascular disease & 6 & $30 / 707$ & $27 / 1,759$ & $P=0.44 ; I^{2}=0 \%$ & 2.88 & $1.63-5.07$ & 0.0003 \\
\hline HIV or immunosuppression & 5 & $7 / 467$ & $6 / 1,635$ & $P=0.56 ; I^{2}=0 \%$ & 3.28 & $1.21-8.89$ & 0.02 \\
\hline \multicolumn{8}{|l|}{ Laboratory indicators } \\
\hline Chest CT images: bilateral lung & 5 & $333 / 386$ & $772 / 1,472$ & $P=0.32 ; I^{2}=15 \%$ & 4.84 & $3.52-6.66$ & $<0.00001$ \\
\hline \multicolumn{8}{|l|}{ White blood cell $\left(\times 10^{9} / \mathrm{L}\right)$} \\
\hline$>10$ & 9 & $112 / 524$ & $98 / 1,628$ & $P=0.001 ; 12=69 \%$ & 3.57 & $1.78-7.18$ & 0.0004 \\
\hline$<4$ & 9 & $160 / 524$ & $445 / 1,628$ & $P<0.00001 ; I^{2}=89 \%$ & 0.59 & $0.25-1.40$ & 0.23 \\
\hline Increased creatinine & 6 & $22 / 304$ & $36 / 989$ & $P=0.04 ; I^{2}=58 \%$ & 1.61 & $0.61-4.28$ & 0.34 \\
\hline Increased lactate dehydrogenase & 6 & $170 / 250$ & $317 / 877$ & $P=0.01 ; I^{2}=65 \%$ & 5.75 & $2.68-12.34$ & $<0.00001$ \\
\hline Increased procalcitonin & 6 & $58 / 280$ & $45 / 772$ & $P=0.25 ; I^{2}=24 \%$ & 3.09 & $1.99-4.81$ & $<0.00001$ \\
\hline Increased total bilirubin & 2 & $20 / 158$ & $65 / 725$ & $P=0.52 ; I^{2}=0 \%$ & 1.48 & $0.87-2.53$ & 0.15 \\
\hline $\begin{array}{l}\text { Increased alanine } \\
\text { aminotransferase }\end{array}$ & 4 & $77 / 248$ & $164 / 858$ & $P=0.32 ; I^{2}=14 \%$ & 1.89 & $1.34-2.66$ & 0.0003 \\
\hline $\begin{array}{l}\text { Increased aspartate } \\
\text { aminotransferase }\end{array}$ & 7 & $141 / 319$ & $194 / 1,000$ & $P=0.09 ; I^{2}=45 \%$ & 3.09 & $1.97-4.84$ & $<0.00001$ \\
\hline Increased C-reactive protein level & 6 & $370 / 411$ & $806 / 1,298$ & $P=0.05 ; I^{2}=56 \%$ & 4.33 & $2.07-9.07$ & 0.0001 \\
\hline
\end{tabular}

*, heterogeneity: $I^{2}<50 \%, P>0.1$, suggesting that the homogeneity of each test was good, and the meta-analysis was performed using the fixed effect model (FE), while in contrast $\left(I^{2}>50 \%, P<0.1\right)$, the random effects model (RE) was used. ${ }^{a}, P$ values indicate differences between severe and non-severe patients. $\mathrm{P}<0.05$ was considered statistically significant. ARDS, acute respiratory distress syndrome; AKI, acute kidney injury; COPD, chronic obstructive pulmonary disease. 

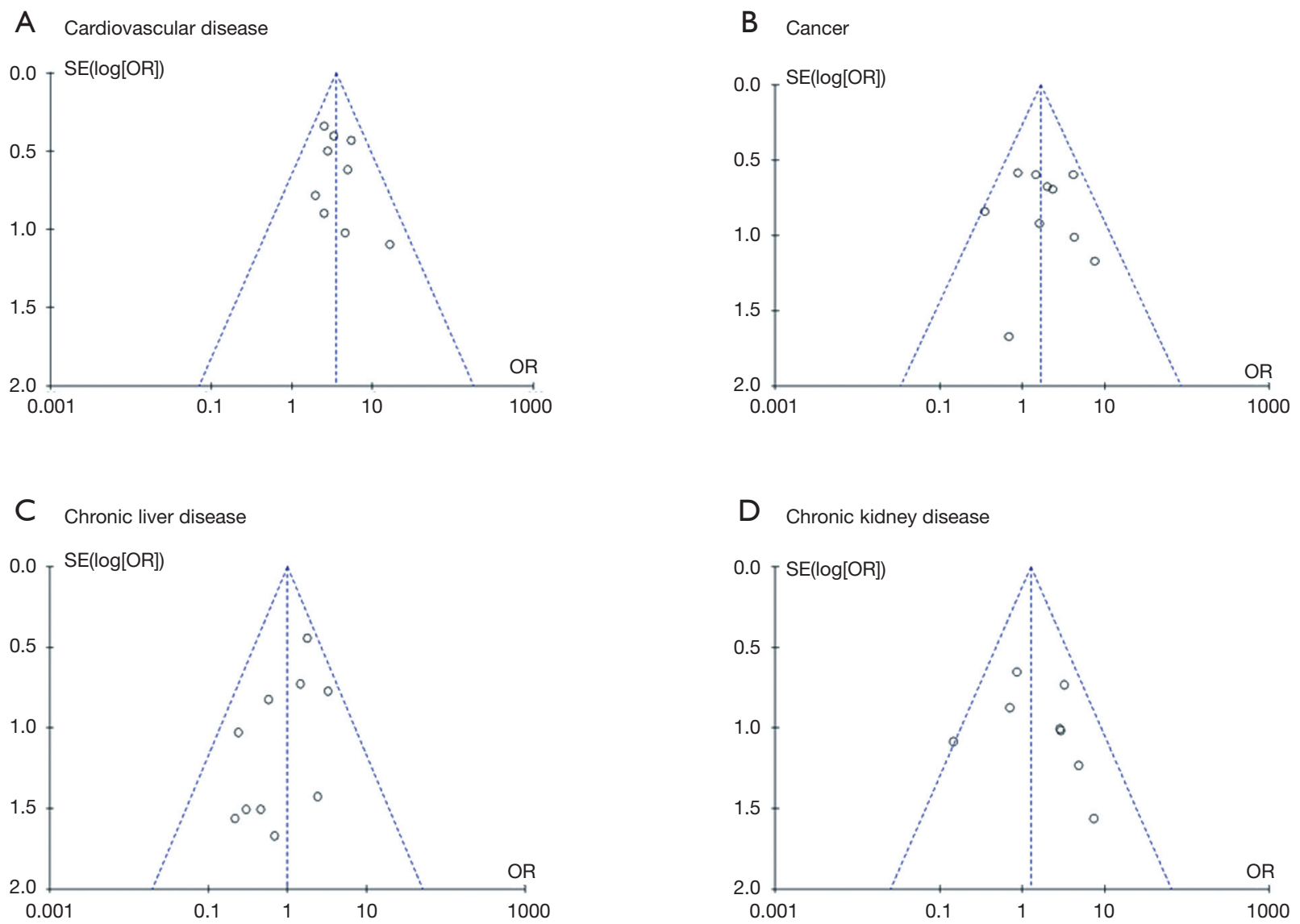

Figure 2 Funnel plots of the comparison of cardiovascular disease, cancer, chronic liver disease, and chronic kidney disease between the two groups. The middle lines represent the OR value of each study: (A) cardiovascular disease: 3.35; (B) cancer: 1.66; (C) chronic liver disease: 0.99; (D) chronic kidney disease: 1.26 .

frequently in the treatment of severe patients than nonsevere patients.

The mortality in the group of severe patients was much higher than that in the group of non-severe patients (OR $=25.85, \mathrm{P}<0.00001)$, but the difference of discharge rate (OR $=0.20, \mathrm{P}=0.001)$ in the group of severe patients was lower than non-severe patients. Moreover, the hospitalization rate between the two groups had no statistical significance $(\mathrm{P}=0.20)$ (Table 3).

\section{Meta-regression analysis: multivariate analysis}

In Table 4, meta-regression analysis showed that patient age, gender, and proportion of severe cases did not significantly impact on the outcomes of any clinical indexes that showed high degree of heterogeneity in the meta-analysis.

\section{Discussion}

We performed a meta-analysis of 16 current high-quality articles on COVID-19, which is the first comprehensive systematic review to compare the clinical characteristics of severe patients and non-severe patients in China. The virus was not only widespread in China, as of April 15, 2020 , there were totally $1,946,523$ confirmed patients in the world, with high mortality in some countries like Algeria (15.74\%), France (15.18\%), Belgium (13.35\%), and Italy $(11.35 \%)$, etc. Therefore, it is urgent to recognize the clinical characteristics of patients infected with the virus (especially severe patients) and take corresponding measures in advance to reduce mortality.

In this study, we found that severe patients were more likely to be manifested with dyspnea, hemoptysis, and the onset of these symptoms might help physicians identify 
Table 3 The difference between severe and non-severe patients in treatments and prognosis

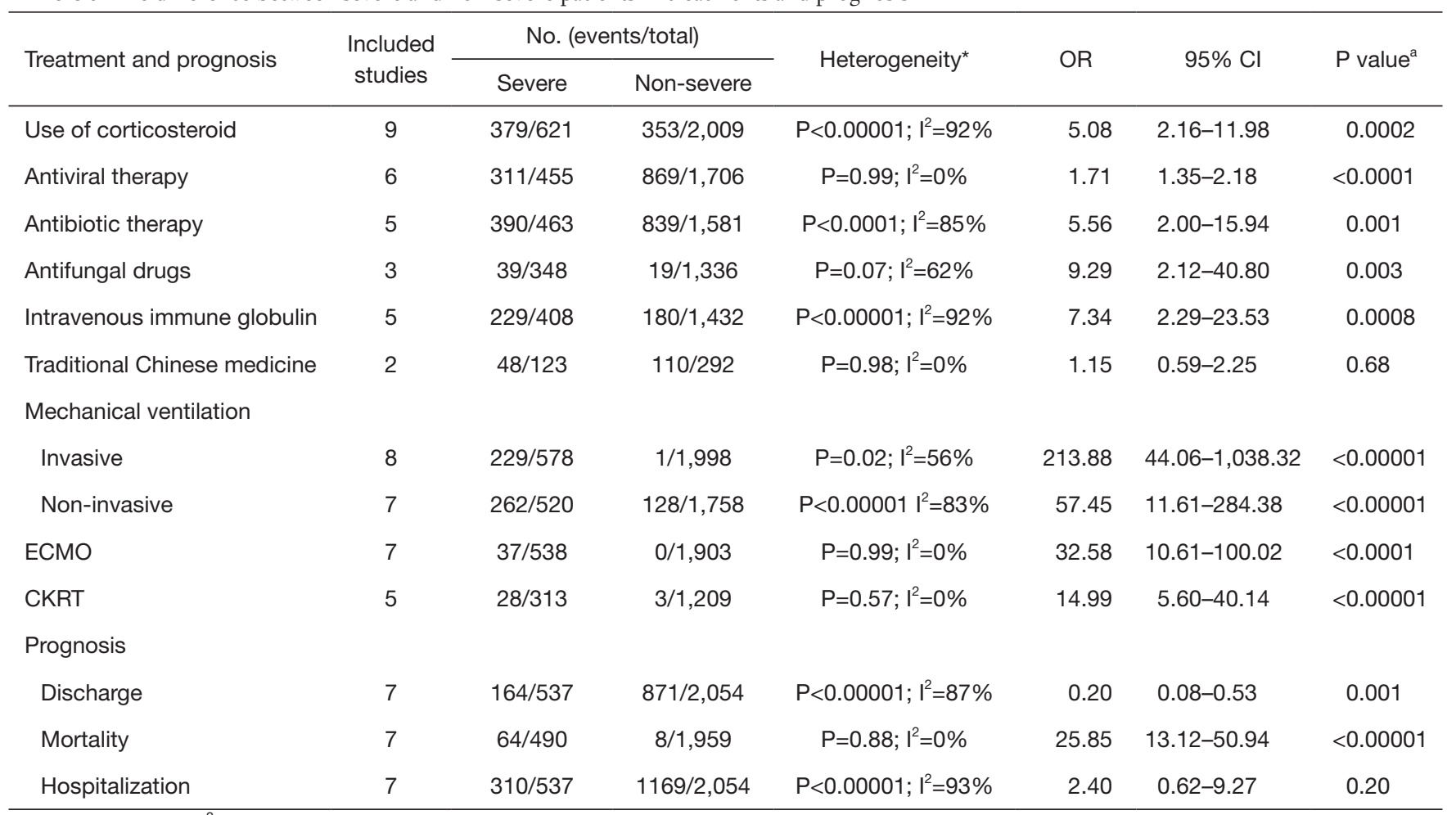

*, heterogeneity: $I^{2}<50 \%, P>0.1$, suggesting that the homogeneity of each test was good, and the meta-analysis was performed using the fixed effect model (FE), while in contrast $\left(I^{2}>50 \%, P<0.1\right)$, the random effects model (RE) was used; ${ }^{2}, P$ values indicate differences between severe and non-severe patients. $\mathrm{P}<0.05$ was considered statistically significant. ECMO, extracorporeal membrane oxygenation; CKRT, continuous kidney replacement therapy.

the severe patients with poor prognosis. In terms of age, the severe patients was generally at a higher level than that of non-severe patients (3-7,9-11,13-18), which might be related to the lower immunity, more health issues and more comorbidities of older patients (6). In addition, this also indicated that the old-age was one of the risk factors leading to serious disease and might have contributed to the poor prognosis in some cases (19). Except for the elderly, patients with diabetes, HIV infection, long-term immunosuppressive therapy, and pregnant women also have relatively low body immunity (20). Therefore, strengthening the immunotherapy could appropriately reduce the severity and mortality of the disease.

Interestingly, our study found that patients' disease severity was related to past smoking history, but not associated with current smoking history. Because there was a lack of research on smoking history of patients infected with COVID-19, the relationship between smoking and COVID-19 was not clear (6), but there had been previous studies $(21,22)$ confirmed that Ex-smoking was one of the risk factors for community-acquired pneumonia (CAP), and the authors (21) also found a significantly decrease in CAP risk in the second year following smoking cessation, which had been attributed to normalisation of immune and inflammatory function of lung tissue. Brake et al. (23) had shown that smoking can upregulate the angiotensinconverting enzyme 2 (ACE2) receptor, which was a known receptor for severe acute respiratory syndrome -coronavirus (SARS-CoV) and human respiratory coronavirus NL638. Additionally, the patients' cumulative smoking volume is more important, and it can indirectly contribute to the severity of the COVID-19 by causing many comorbidities like COPD, malignancy and cardiovascular diseases, etc.

The underlying comorbidities like hypertension, Cardiovascular disease, malignancy, COPD, cerebrovascular disease, diabetes, and HIV or other immunosuppression disease were more prevalent among severe patients, which proved that the above-mentioned comorbidities as risk factors could make the disease worse and also might be associated with increased mortality (20). It is worth noting 
Table 4 The outcomes of meta-regression analysis: multivariate analysis

\begin{tabular}{|c|c|c|c|c|}
\hline Clinical indexes & \multicolumn{4}{|c|}{ Multivariate analysis ( $\mathrm{P}$ value) } \\
\hline \multicolumn{5}{|l|}{ Symptoms } \\
\hline Fever & 0.606 & 0.943 & 0.725 & 0.699 \\
\hline Cough & 1.169 & 0.280 & 0.051 & 0.137 \\
\hline Diarrhea & 0.964 & 0.874 & 0.868 & 0.907 \\
\hline Sputum production & 0.942 & 0.963 & 0.844 & 0.954 \\
\hline Anorexia & 0.328 & 0.349 & 0.318 & 0.329 \\
\hline \multicolumn{5}{|l|}{ Complications } \\
\hline $\mathrm{AKI}^{*}$ & 0.148 & 0.698 & 0.953 & - \\
\hline Acute cardiac injury* & 0.485 & 0.901 & 0.486 & - \\
\hline \multicolumn{5}{|l|}{ Comorbidities } \\
\hline Any & 0.533 & 0.519 & 0.241 & 0.495 \\
\hline Hypertension & 0.186 & 0.074 & 0.131 & 0.178 \\
\hline \multicolumn{5}{|l|}{ Laboratory indicators } \\
\hline \multicolumn{5}{|l|}{ White blood cell $\left(\times 10^{9} / \mathrm{L}\right)$} \\
\hline$>10$ & 0.345 & 0.588 & 0.898 & 0.512 \\
\hline Increased lactate dehydrogenase & 0.313 & 0.367 & 0.374 & 0.271 \\
\hline Increased C-reactive protein level & 0.787 & 0.748 & 0.727 & 0.613 \\
\hline \multicolumn{5}{|l|}{ Treatment } \\
\hline Use of corticosteroid & 0.847 & 0.984 & 0.766 & 0.898 \\
\hline Antibiotic therapy ${ }^{*}$ & 0.431 & 0.089 & 0.680 & - \\
\hline Antifungal drugs* & 0.331 & 0.418 & 0.332 & - \\
\hline Intravenous immune globulin* & 0.097 & 0.096 & 0.526 & - \\
\hline Invasive mechanical ventilation & 0.537 & 0.501 & 0.794 & 0.620 \\
\hline Non-invasive mechanical ventilation & 0.752 & 0.450 & 0.222 & 0.481 \\
\hline \multicolumn{5}{|l|}{ Prognosis } \\
\hline Discharge & 0.948 & 0.989 & 0.916 & 0.985 \\
\hline Hospitalization & 0.503 & 0.705 & 0.558 & 0.556 \\
\hline
\end{tabular}

*, due to the limited number of included studies, the multivariate analysis can't be performed in these indexes, so we just performed the univariate analysis. $P$ values in these indexes represents the outcomes of univariate analysis. 
that according to previous research, we found that very few cancer patients were infected with this virus, which was contrary to the phenomenon that cancer patients had low immunity and were easily infected. According to our clinical data, the reason may be that cancer patients realized their condition was not ideal, and paid more attention to personal protection and rarely went out to contact with outsiders, thus greatly reducing the risk of infection. But once cancer patients were infected, their prognosis would be worse than that of patients without cancer (24).

We also found that severe patients have significantly higher risk to have the complications of ARDS, AKI, acute cardiac injury, secondary infection, and shock, which were consistent with previous studies, and these complications might be the potential predictors of the severity of COVID-19 (3,5,11-18). In addition to these complications, previous studies had also reported that severe patients are prone to other complications such as acute liver injury etc., for example, as is shown in $\mathrm{Xu}$ et al.'s study (25), the liver biopsy specimens of the patient with COVID-19 showed moderate microvascular steatosis and mild lobular and portal activity.

In terms of laboratory indicators, severe patients have numerous laboratory abnormalities, such as higher levels of D-dimer, PCT, WBC, LDH, ALT, AST, creatine kinase and CRP, but lower levels of lymphocyte count and platelet count than non-severe patients. The higher CRP, PCT, D-dimer concentration and leukocyte counts might represent more prominent inflammation in severe patients, and the higher leukocyte count and PCT might also be due to secondary bacterial infection (6). The reduction of lymphocyte count indicated that this coronavirus might mainly act on lymphocytes and damage them, especially T lymphocytes. The translocation of lymphocyte from peripheral blood to lungs might also cause to the reduced lymphocytes $(3,7,8,20)$. Neutrophilia might be related to cytokine storm induced by virus invasion, which generate a series of immune responses and cause changes in peripheral leukocytes and immune cells (20). The elevated LDH might be associated with myocardia injury, hepatic injury and kidney injury that related to direct effects of the virus, hypoxia, and shock (8). The elevating of ALT and AST might be also associated with the hepatic injury caused by the direct effects of the virus, drug hepatotoxicity or immune-mediated inflammation (such as cytokine storm and pneumonia-associated hypoxia, etc.) $(3,26)$. A previous study has described that lymphocyte count, LDH, neutrophil count, and CRP were highly correlated to the acute lung injury and might be predictors of disease severity (27), and the conclusion was almost in line with our study. Moreover, the higher D-dimer, PCT, WBC count, ALT, and AST might also be predictors of severity in this study.

The chest CT of severe patients mainly showed bilateral lung involvement, which is consistent with previous studies (28-31). Not only that, many research reports on COVID-19 indicated that most patients have CT manifestations with multiple lobes involvement $(19,28,29)$, and showed patchy/punctate ground glass opacities, etc. (19,29-34). The posterior and peripheral lung predominant distribution in some studies was also very characteristic (28-31).

This study had several limitations: (I) all the studies are from China, so the results are difficult to represent the clinical characteristics of populations around the world. In contrast, the results of this study were more suitable for the Chinese population; (II) the combined indicators were not so comprehensive because of the limited numbers of included articles, such as some complications and comorbidities, so further study were necessary; (III) all studies included in this meta-analysis were retrospective studies with inevitable possible bias. Therefore, based on the above limitations, the conclusions of this meta-analysis still need to be verified by more relevant studies from multicenters with larger sample size.

\section{Conclusions}

The severity of COVID-19 could be evaluated by age, radiologic finding, symptoms such as dyspnea, Hemoptysis etc., some laboratory indicators such as D-dimer, PCT, WBC count, LDH, ALT, AST, neutrophil count, C-reactive protein level and lymphocyte count etc., and smoking history, especially the ex-smokers. Compared with non-severe patients, severe patients were more likely to have complications such as ARDS, AKI, shock, etc. Comorbidities including hypertension, cardiovascular disease, COPD, and diabetes etc. were the risk factors for the disease to be severer and could also cause higher mortality, but the chronic liver disease and chronic kidney disease were not associated the severity of COVID-19.

\section{Acknowledgments}

We acknowledge all the medical staff who participated in this study.

Funding: This work was supported by National Natural 
Science Foundation of China (81670036), Mandatory Subject Project of Medical Research Fund of Guangdong Province (C2019029)/Self-funded Science and Technology Plan Project of Guangdong Department of Science and Technology (2019ZC0029), Guangdong High Level University Clinical Cultivation Project (201721020), State Key Laboratory of Respiratory Disease-The Independent Project (SKLRD-MS-201905), Characteristic Innovation Projects of Universities in Guangdong Province (2018KTSCX181), Special Project on Prevention and Control of Novel Coronavirus Pneumonia Epidemic in Universities in Guangdong Province (2020KZDZX1162).

\section{Footnote}

Reporting Checklist: The authors have completed the PRISMA reporting checklist. Available at http://dx.doi. org/10.21037/jtd-20-1743

Conflicts of Interest: All authors have completed the ICMJE uniform disclosure form (available at http://dx.doi. org/10.21037/jtd-20-1743). All authors have no conflicts of interest to declare.

Ethical Statement: The authors are accountable for all aspects of the work in ensuring that questions related to the accuracy or integrity of any part of the work are appropriately investigated and resolved.

Open Access Statement: This is an Open Access article distributed in accordance with the Creative Commons Attribution-NonCommercial-NoDerivs 4.0 International License (CC BY-NC-ND 4.0), which permits the noncommercial replication and distribution of the article with the strict proviso that no changes or edits are made and the original work is properly cited (including links to both the formal publication through the relevant DOI and the license). See: https://creativecommons.org/licenses/by-nc-nd/4.0/.

\section{References}

1. National Health Commission of the people's Republic of China. The Guidelines for the Diagnosis and Treatment of New Coronavirus Pneumonia (fifth edition). Available online: www.nhc.gov.cn/yzygj/s7653p/202002/3b09b894ac 9b4204a79db5b8912d4440.shtml

2. Stang A. Critical evaluation of the Newcastle-Ottawa scale for the assessment of the quality of nonrandomized studies in meta-analyses. Eur J Epidemiol 2010;25:603-5.

3. Wan S, Xiang Y, Fang W, et al. Clinical Features and Treatment of COVID-19 Patients in Northeast Chongqing. J Med Virol 2020;92:797-806.

4. Qin C, Zhou L, Hu Z, et al. Dysregulation of immune response in patients with COVID-19 in Wuhan, China. Clin Infect Dis 2020;71:762-8.

5. Guan WJ, Ni ZY, Hu Y, et al. Clinical Characteristics of Coronavirus Disease 2019 in China. N Engl J Med 2020;382:1708-20.

6. Zhang JJ, Dong X, Cao YY, et al. Clinical characteristics of 140 patients infected with SARS-CoV-2 in Wuhan, China. Allergy 2020;75:1730-41.

7. Tian S, Hu N, Lou J, et al. Characteristics of COVID-19 infection in Beijing. J Infect 2020;80:401-6.

8. Zhang G, Zhang J, Wang B, et al. Analysis of clinical characteristics and laboratory findings of 95 cases of 2019 novel coronavirus pneumonia in Wuhan, China: a retrospective analysis. Respir Res 2020;21:74.

9. Chu J, Yang N, Wei Y, et al. Clinical Characteristics of 54 medical staff with COVID-19: A retrospective study in a single center in Wuhan, China. J Med Virol 2020;92:807-13.

10. Wu J, Li W, Shi X, et al. Early antiviral treatment contributes to alleviate the severity and improve the prognosis of patients with novel coronavirus disease (COVID-19). J Intern Med 2020;288:128-38.

11. Wang D, Hu B, Hu C, et al. Clinical Characteristics of 138 Hospitalized Patients With 2019 Novel CoronavirusInfected Pneumonia in Wuhan, China. JAMA 2020;323:1061-9.

12. Huang C, Wang Y, Li X, et al. Clinical features of patients infected with 2019 novel coronavirus in Wuhan, China. Lancet 2020;395:497-506.

13. Zheng F, Tang W, Li H, et al. Clinical characteristics of 161 cases of corona virus disease 2019 (COVID-19) in Changsha. Eur Rev Med Pharmacol Sci 2020;24:3404-10.

14. Mao L, Jin H, Wang M, et al. Neurologic Manifestations of Hospitalized Patients With Coronavirus Disease 2019 in Wuhan, China. JAMA Neurol 2020;77:683-90.

15. Du RH, Liu LM, Yin W, et al. Hospitalization and Critical Care of 109 Decedents with COVID-19 Pneumonia in Wuhan, China. Ann Am Thorac Soc 2020;17:839-46.

16. Feng Y, Ling Y, Bai T, et al. COVID-19 with Different Severity: A Multi-center Study of Clinical Features. Am J Respir Crit Care Med 2020;201:1380-8.

17. Chen G, Wu D, Guo W, et al. Clinical and immunological features of severe and moderate coronavirus disease 2019. J Clin Invest 2020;130:2620-9. 
18. Cai Q, Huang D, Ou P, et al. COVID-19 in a Designated Infectious Diseases Hospital Outside Hubei Province, China. Allergy 2020;75:1742-52.

19. Liu K, Fang YY, Deng Y, et al. Clinical characteristics of novel coronavirus cases in tertiary hospitals in Hubei Province. Chin Med J (Engl) 2020;133:1025-31.

20. Chen N, Zhou M, Dong X, et al. Epidemiological and clinical characteristics of 99 cases of 2019 novel coronavirus pneumonia in Wuhan, China: a descriptive study. Lancet 2020;395:507-13.

21. Almirall J, Bolíbar I, Serra-Prat M, et al. New evidence of risk factors for community-acquired pneumonia: a population-based study. Eur Respir J 2008;31:1274-84.

22. Almirall J, González CA, Balanzó X, et al. Proportion of community-acquired pneumonia cases attributable to tobacco smoking. Chest 1999;116:375-9.

23. Brake SJ, Barnsley K, Lu W, et al. Smoking Upregulates Angiotensin-Converting Enzyme-2 Receptor: A Potential Adhesion Site for Novel Coronavirus SARS-CoV-2 (Covid-19). J Clin Med 2020;9:841.

24. Liang $W$, Guan $W$, Chen R, et al. Cancer patients in SARS-CoV-2 infection: a nationwide analysis in China. Lancet Oncol 2020;21:335-7.

25. Xu Z, Shi L, Wang Y, et al. Pathological findings of COVID-19 associated with acute respiratory distress syndrome. Lancet Respir Med 2020;8:420-2.

26. Zhang C, Shi L, Wang FS, Liver injury in COVID-19:

Cite this article as: Zhang T, Huang WS, Guan W, Hong Z, Gao J, Gao G, Wu G, Qin YY. Risk factors and predictors associated with the severity of COVID-19 in China: a systematic review, meta-analysis, and meta-regression. J Thorac Dis 2020;12(12):7429-7441. doi: 10.21037/jtd-20-1743 management and challenges. Lancet Gastroenterol Hepatol 2020;5:428-30.

27. Liu Y, Yang Y, Zhang C, et al. Clinical and biochemical indexes from 2019-nCoV infected patients linked to viral loads and lung injury. Sci China Life Sci 2020;63:364-74.

28. Song F, Shi N, Shan F, et al. Emerging Coronavirus 2019nCoV Pneumonia. Radiology 2020;295:210-7.

29. Xu X, Yu C, Qu J, et al. Imaging and clinical features of patients with 2019 novel coronavirus SARS-CoV-2. Eur J Nucl Med Mol Imaging 2020;47:1275-80.

30. Shi H, Han X, Jiang N, et al. Radiological findings from 81 patients with COVID-19 pneumonia in Wuhan, China: a descriptive study. Lancet Infect Dis 2020;20:425-34.

31. Chung M, Bernheim A, Mei X, et al. CT Imaging Features of 2019 Novel Coronavirus (2019-nCoV). Radiology 2020;295:202-7.

32. Pan $Y$, Guan H, Zhou S, et al. Initial CT findings and temporal changes in patients with the novel coronavirus pneumonia (2019-nCoV): a study of 63 patients in Wuhan, China. Eur Radiol 2020;30:3306-9.

33. Russell CD, Millar JE, Baillie JK. Clinical evidence does not support corticosteroid treatment for 2019-nCoV lung injury. Lancet 2020;395:473-5.

34. Chen L, Liu H G, Liu W, et al. Analysis of clinical features of 29 patients with 2019 novel coronavirus pneumonia. Zhonghua Jie He He Hu Xi Za Zhi 2020;43:E005. 